\title{
Editorial: Policy, Practice and Research in Built Environment Education
}

\section{Angela Million}

Professor, Department of Urban and Regional Planning, Technische Universität Berlin, Germany

\section{Rosie Parnell}

Associate Professor, Department of Architecture and Built Environment, Northumbria University, Newcastle, UK

\author{
Thomas Coelen \\ Professor, Siegen Centre for Educational Research (SiZe), \\ University of Siegen, Germany
}

Built environment education (BEE) for children and young people incorporates a broad field of activities and approaches, drawn from areas such as environmental, architectural, design, and (visual) arts education. All of these types of learning can be positioned under the BEE umbrella through their use of buildings, places and spaces as topics and contexts for learning (Uttke, 2012). A term equally often used to describe such activities is children's architectural education.

The broad aim of built environment education is to help children and young people develop an understanding of architectural design and related decision-making processes. Two potentially contrasting - but not mutually exclusive - understandings emerge within this field:

- First is an emphasis on processes, with the intention of familiarising children and young people (and adults) with the methods and approaches used to produce, reproduce and design spaces. Programmes in this realm are intended to help participants understand spatial design processes and their results, and to play an active role in such processes. These programmes thus also provide insights into how democratic society works.

- Second is an understanding of BEE which frames the built environment as a resource for learning. This learning might be framed around maths, physics, art and crafts, geography or history; in fact just about any typical school subject or even topics of informal learning. The intention is that each of these disciplinary understandings is rooted in a simultaneous, sometimes incidental, understanding of the built environment.

The wide range of aims of BEE are captured by PLAYCE international association of architecture education. The association's statement of aims was constructed through a dialogic process involving BEE educators from around the world (see Table 1). The result is distributed across architecture-, childand education-focused aims, offering a framework for understanding the potential scope and impact of BEE.
In practice, the emphasis differs depending on the particular organisations or providers involved. Planning and design professionals in the field, for example, tend to stress the intention to enable young people, as future adult citizens, to play an effective role in the creation of an architecture that exhibits consideration, sustainability and respect for its social and historical context (UIA, 2008).

\footnotetext{
'The culture of building is related to ethics and aesthetics, not to mention an awareness of social and environmental issues; motivation, economic reasoning, creative imagination and artistic potential. This calls for a capable avant-garde whose members each get involved within their own fields of activity and can come together to form initiatives. However, they cannot do this in private: a discerning public sphere - the media, public bodies, associations, schools - is the catalyst which will produce results' (own translation, Weeber, Weeber and Kähler, 2005: p. 7).
}

In contrast to this perspective, pedagogical professionals in the field of BEE tend to stress the intention to enable young people to see and feel, adopt and sometimes also more immediately shape their everyday environment. The built environment becomes a medium through which to learn. Nadansky (2012) helpfully identifies the following topics, commonly found across BEE:

- a feel for the urban and architectural spaces public/private, indoors/outside - where the subjects live and act

an awareness of the rules, rights and responsibilities involved in planning and designing the built environmen

- an understanding of our historical structural legacy and works of modern architecture

- knowledge of the relationships between the built and natural environment and the link between sustainable development and quality of life

- the necessary vocabulary to discuss the quality of buildings and outside areas and how they relate to community and public life 
Table 1. The aims of PLAYCE (Source: www.playce.org)

\author{
Architecture-focused aims \\ To promote reflection on and constructive criticism of the built environment and related practices. \\ To support built environment professionals in working with children in the design process. \\ To support multi-disciplinary collaboration between professionals and children. \\ To improve the built environment.

\section{Child-focused aims} \\ To broaden children's experience of the built environment. \\ To promote enjoyment and exploration of the built environment. \\ To promote the development and use of creative skills and processes. \\ To support children's identification with the environment and society. \\ To support children in experiencing the richness of cultural diversity.

\section{Education-focused aims} \\ To support the use of a diversity of approaches to learning \\ To support the use of architectural education in the school curriculum, as a vehicle for multidisciplinary learning \\ To encourage creative and critical thinking. \\ To support architectural education in informal education. \\ To promote the role of built environmental professionals in education.
}

knowledge of analytical and problem-solving methods used in the design process

a ability to work in a team, spot and describe problems and find creative solutions to them

an opportunity to experiment with methods, forms and materials

- programmes teaching sensitivity and imagination, taste and discernment.

Examining BEE from a third direction, however, we can also understand this to be a learning process for the facilitating adults involved: 'If they are to hold a dialogue with users, then designers, architects and urban planners must be taught more about users' needs and social and communal aspects during their training. Their education should more strongly promote their ability to communicate, so that they are prepared to engage with social groups.' (own translation: Deutscher Kulturrat, 1995: p. 140).

Though architects and planners might play the role of educator at various stages of a design engagement process (Million and Parnell, 2017, see also Figures 1 and 2: University students in urban planning and design of TU Berlin in a workshop with 9th grade high school students of Campus EFEUWEG, Berlin - the workshop was programmed and moderated by the university students themselves), there is reciprocity in this process. Through BEE, a facilitator might learn a great deal about user experiences, public perceptions, responses and the appropriateness of the various engagement techniques that he or she explores. BEE therefore provides a safe space within which not only children, but also professionals, might explore and experiment, taking risks from which they can learn.

There has been a noticeable increase in the number of BEE activities, events, conferences and workshops worldwide

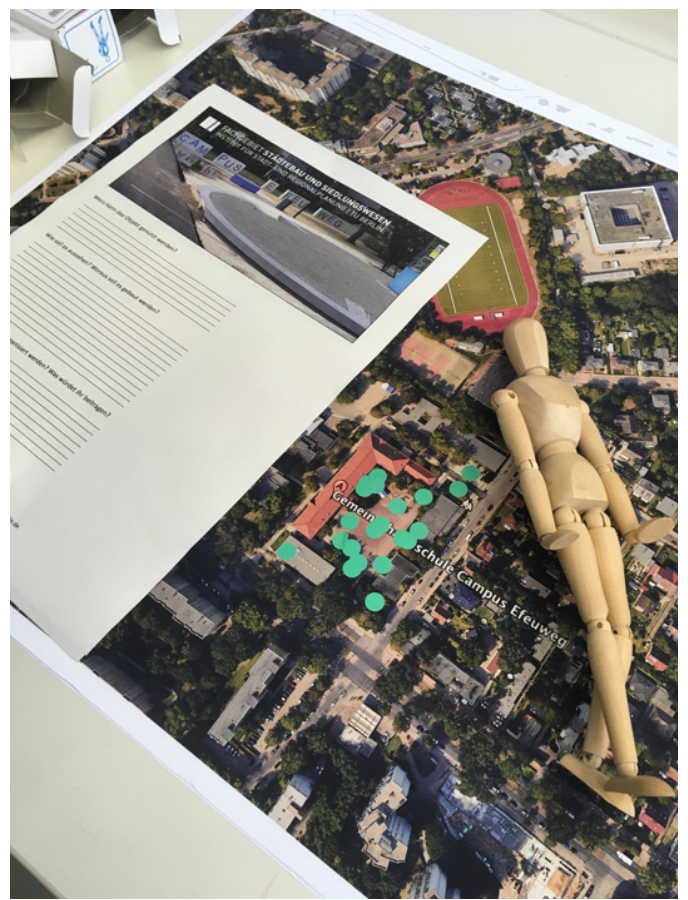

Figure 1. Participatory and educational life project for Master students of urban design and planning. The task was to be co-designer as well as educator to high school students working together on a school yard design

since 2000, bringing together a diverse range of people in the field: from education officers in museums and dedicated architecture centres; people located in the wider cultural and third sector arts; design and planning practitioners and architects working either independently or through their professional bodies; and, of course, teachers in schools and 
Editorial: Policy, Practice and Research in

Built Environment Education

Million, Parnell and Coelen
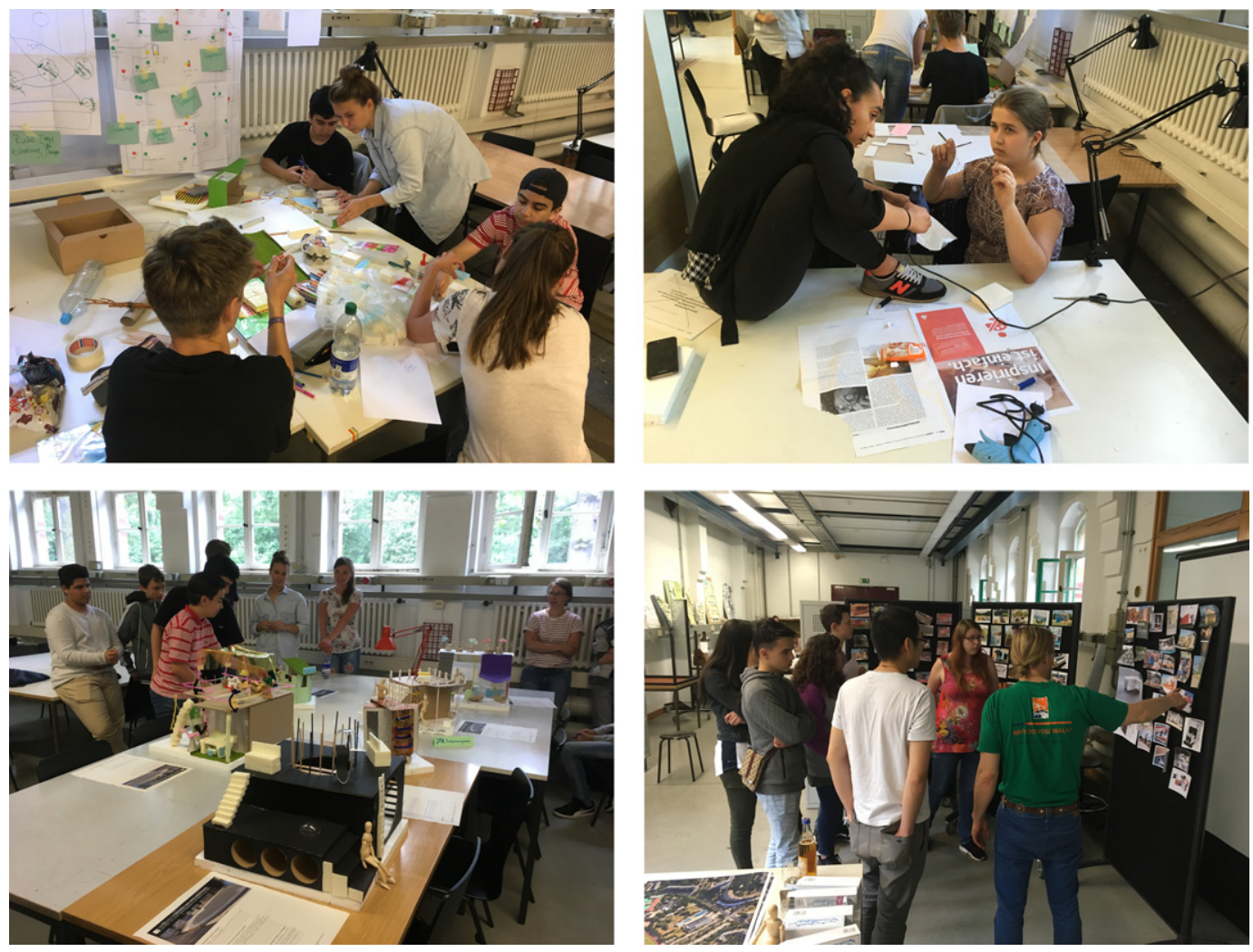

Figure 2. Workshop located in university studio space and programmed by university students for 9th grade high school students.

nursery teachers in kindergartens and youth workers in youth centres. It is also apparent that educational activities are increasingly being incorporated into 'live' planning and design processes. Despite a lively and active exchange of knowledge between BEE practitioners, this conversation has rarely extended to include the academic world. The field, therefore, still lacks a strong peer-reviewed research-base and remains under-theorised.

The following special issue contributes towards closing this research gap, addressing policy and practice in Built Environment Education (BEE) and its relevance to public participation in architecture, urban design and urban planning. Antje Lehn and Victoria Derr pursue questions that both scope and challenge the boundaries and theoretical underpinnings of the field. Derr, for example, demonstrates the way in which BEE can be understood as a pedagogical framework for reconceptualising related educational traditions: in this case the wellestablished and overlapping field of environmental education. She suggests that 'built environment education holds promise as an integrative context for participatory learning in the city', providing what she calls 'a means to consider an often-challenging goal for environmental education - the deliberate integration of methods that teach and promote action competence (McLaren and Hammond, 2005) through participatory practices (Chawla and Derr, 2012; Hart, 1997)'. It becomes clear that the papers in the issue broadly share a sometimes implicit, sometimes explicit understanding of space, summarised by Lehn, as 'a construction process permanently redefined by the users rather than as a static construction.' Teresa Strachan similarly frames her work in relation to a Lefebvrian perspective, suggesting that space is constructed '... not only through "representational space" as lived by people, but also through "spatial practice" where daily routines, networks and actions determine the value of that space (Lefebvre, 1991).' Within such a theoretical framework, the importance of BEE as a vehicle for the exploration, articulation and valuing of children and young people's spatial practices and experiences becomes clear.

A range of sectors is represented in the papers, from universities - where students are supported to work directly with children - to museums. Marta Brkovic Dogic explains that museums, in particular, are emerging as a key site for BEE, offering diverse programmes internationally. She offers a review of practice in this context, adding to our knowledge and the scarce academic literature available, through an 
analysis of interviews with museum-based providers in Sweden, Germany, the USA and Hungary. Reviewing some of the suggestions that have been made about the impacts of BEE on children and young people, Brkovic Dogic notes a general lack of reported empirical evidence for learning outcomes. So what can be claimed at this stage in BEE's evolution?

BEE has been reported by teachers to enrich the curriculum and aid learning and achievement by providing 'first-hand, relevant experiences that contextualise learning' (Kendall et al., 2007a; see also Kendall et al., 2007b). Beyond disciplinary boundaries, BEE has been shown to develop children's critical thinking and promote self-confidence and communication skills, allowing clear presentation of social, political and economic facts, ultimately enabling participation in decisionmaking processes (BMVBW 2001; Busse and Welzel, 2012; Deutscher Kulturrat, 1995). The architectural knowledge and understanding developed through such approaches - about materials, structure, construction and sustainability or the ability to visualise and describe imagined experiences of spaces - have enabled students to confidently judge and articulate for themselves the value of a building, space or design (Parnell et al., 2008). This Change Project engaged more than 700 children and young people with architectural education and provided evidence of these areas of development. However, the evidence-base does indeed need strengthening through further empirical studies.

One interesting forthcoming example of empirical research, the Wüstenrot Project, involving an interdisciplinary team of researchers from Siegen University and TU Berlin in Germany, will examine relevant experiences of BEE within the biographies of young people (Coelen and Million, 2018). The project will seek to identify not only immediate impacts of a course, workshop, or seminar, but also any sustained or new individual outcomes in the everyday lives of the young people, one year later. Finally, Million and Parnell are working towards a co-authored book surveying a range of relevant policy and specific examples of practice internationally, highlighting specific 'beacon' organisations or programmes within a variety of sectors. Through these case studies, the intention is to provide readers with insights about how BEE success can be achieved, and the conditions that support theoretical, strategic and practical success at local, regional, national and even international levels. We suggest that the cases in this special issue might similarly be read with a view to informing and inspiring both the theory and the practice of BEE.

\section{REFERENCES}

BMVBW (Bundesministerium für Verkehr, Bau- und Wohnungswesen) (2001) Statusbericht, Baukultur in Deutschland, Ausgangslage und Empfehlungen. BMVBW, Berlin, Germany, p. 53 (in German)

Busse KP and Welzel B (2012) Stadtspäher in Hagen - Baukultur in Schule und Universität, Wüstenrot Stiftung ( $\mathrm{Hg}$.) (in German).

Chawla L and Derr V (2012) The development of conservation behaviors in childhood and youth. In Handbook of Conservation Psychology (Clayton S (ed.)). Oxford University Press, New York, NY, USA, pp. 527-555.

Coelen and Million (2018) http://urbandesign.staedtebau.tu-berlin. de/lernen-in-der-baukulturellen-bildung (accessed 22/01/2018).

Deutscher Kulturrat (1995) »Gestaltung des Alltags« Kulturelle Bildung in Design und Baukultur, Dokumentation der gleichnamigen Fachtagung des Deutschen Kulturrates vom 3-4. Mai 1995 in Essen, Zeche Zollverein. Fotosatz Froitzheim, Bonn, Germany, p. 140 (in German)

Hart RA (1997) Children's Participation: The Theory and Practice of Involving Young Citizens in Community Development and Environmental Care. Routledge, Abingdon, UK.

Kendall S, Murfield J and Wilkin A (2007a) Engaging Places: Teacher Research. Final Report. DCMS, London, UK, pp. 17-18. See http://www.nfer.ac.uk/publications/BEE03/ (accessed 14/10/2017).

Kendall S, Murfield J, White R and Wilkin A (2007b) Bridging the Gap: a Synthesis of Research into the Supply and the Demand of Built Environment Education in Schools (Engaging Places Research Summary). DCMS, London, UK. See http://www.nfer.ac. uk/publications/BEE01/ (accessed 14/10/2017).

Lefebvre H (1991) The Production of Space. Blackwell, Oxford, UK.

McLaren M and Hammond W (2005) Integrating education and action in environmental education. In Environmental Education and Advocacy (Johnson EA and Mappin MJ (eds)). Cambridge University Press, Cambridge, UK, pp. 267-291.

Million A and Parnell R (2017) Educative planner. disP - The Planning Review 53(2): 78-79.

Nadansky M (2012) Architektur in der kulturellen Bildung. Dossier Kulturelle Bildung bpb. Zugegriffen: 1. Dezember 2013. See http://www.bpb.de/gesellschaft/kultur/kulturelle-bildung/ 137927/architektur-in-der-kulturellen-bildung (accessed 22/01/2018) (in German).

Parnell R, Torrington J, Procter L, Ward N and Elliott C (2008) The Change Project: Engaging Children and Young People with Architecture and the Built Environment. Executive Summary. Unpublished report for the Paul Hamlyn Foundation. See https://www.sheffield.ac.uk/polopoly_fs/1.73030!/file/The_Change_ Project_Executive_Summary.pdf (accessed 14/10/2017).

UIA (International Union of Architects) (ed.) (2008) Built Environment Education Guidelines (2nd edn). See http://uiabee.riai. ie/downloads/uia_bee_en.pdf (accessed 22/01/2018).

Uttke A (2012) Towards the future design and development of cities with built environment education. experiences of scale, methods, and outcomes. Procedia - Social and Behavioral Sciences 45: 3-13, https://doi.org/10.1016/j.sbspro.2012.06.537.

Weeber R, Weeber H and Kähler G (2005) Baukultur! Informationen Argumente - Konzepte. Zweiter Bericht zur Baukultur in Deutschland (S. 7) (in German). 